\title{
Nerd fashion: consumo de heróis e vilões, tendência ou paixão?
}

Nerd fashion: consumption of heroes and villains, trend or passion?
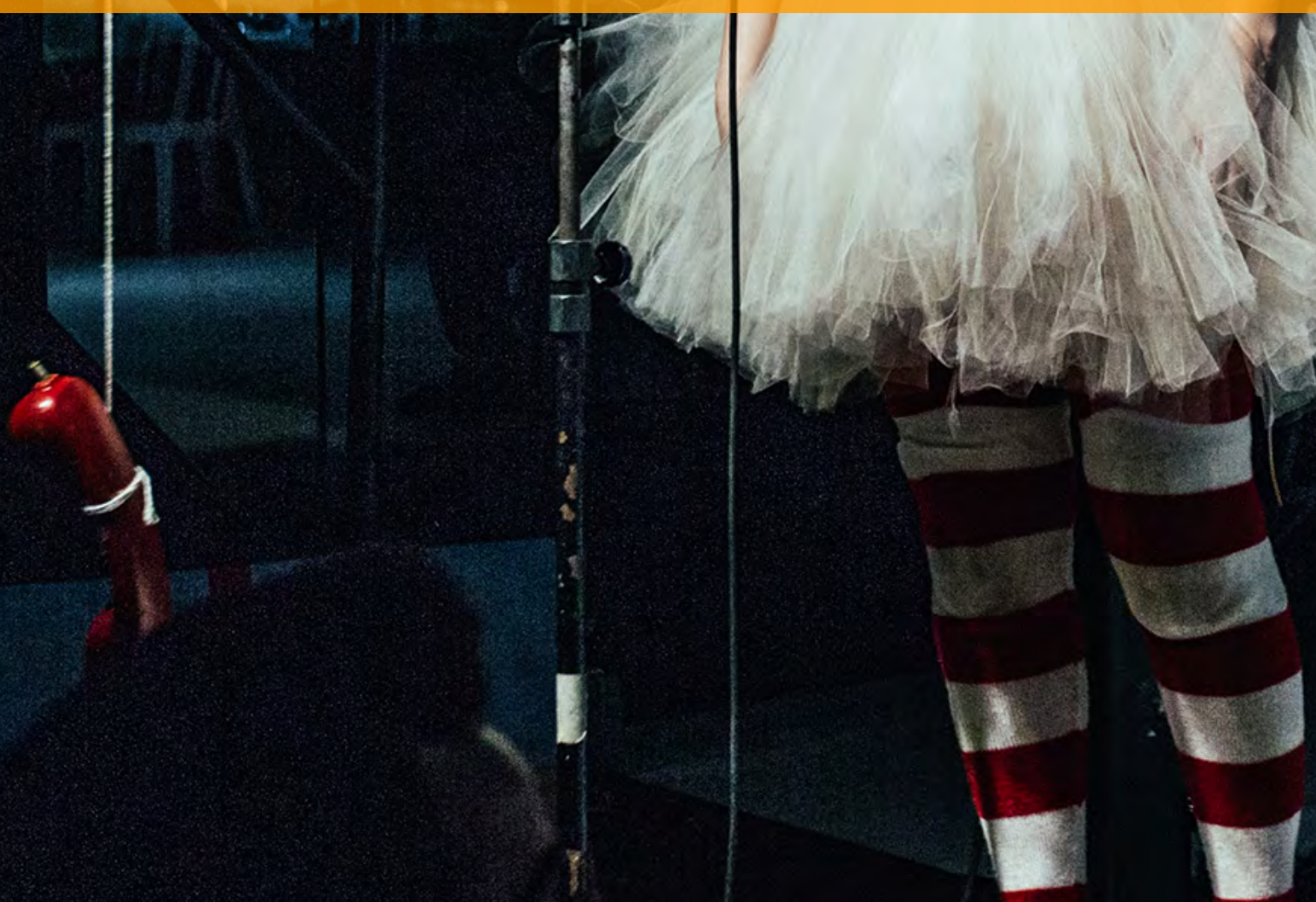


\section{MARCUS DICKSON OLIVEIRA CORREA ${ }^{1}$}

ORCID: https://orcid.org/0000-0001-9760-5628

\section{MILENA CASTRO 2}

ORCID: https://orcid.org/0000-0002-3838-7234

[resumo] Este artigo pretende analisar a cultura de consumo nerd fashion, mercado de moda pautada em estampas de vestuário baseadas em HQs, heróis, vilões, games, filmes e animações. Partindo das concepções de fast fashion traçamos um cenário instigante e criativo que envolve gerações diferentes de pessoas com estilos voltados para um sentimento de copertencimento que conecta umas às outras a partir de um universo que propõe representações simbólicas de coisas simples do cotidiano urbano. Esta investigação gira em torno do que Michel Maffesoli (1998) chama de "época das tribos", que compõe um novo processo de massificação no qual os sujeitos históricos se arranjam na busca de conexões de afetividade e interesse comum com o outro.

\section{[palavras-chave] Fast fashion. Tribos emocionais. Consumo nerd-geek. Moda. Comunicação.}

[abstract] The objective of this essay is to analyze the consumer culture of nerd fashion, a fashion market maked by prints for clothing based on comics, heroes, villains, games, movies and animations. Starting from the diferente concepts of fast fashion, we draw an instigating and creative scenario involving different generations of people with styles oriented towards a feeling of belonging, which connects each other through a universe proposing symbolic representations of simple things of urban everyday life. This research revolves around what Michel Maffesoli (1988) names as "time of the tribes", which composes a new process of massification in which historical subjects find themselves in search of connections of affectivity and common interests with each other.

[keywords] Fast fashion. Emotional tribe. Nerd-geek consumption. Fashion. Communication

Recebido em: 24-02-2019.

Aprovado em: 03-04-2019.

\footnotetext{
1 Mestre em Comunicação, Cultura e Amazônia pela Universidade Federal do Pará e professor/coordenador adjunto dos cursos de publicidade e propaganda e jornalismo da Faculdade Estácio do Pará. E-mail: marcus.correa@estacio.br. Lattes: http://lattes.cnpq.br/0657641895780565.

2 Mestre em Comunicação, Linguagem e Cultura na Universidade da Amazônia e professora do curso de Moda da Faculdade Estácio do Pará. E-mail: castroarqui@gmail.com. Lattes: http://lattes.cnpq. br/3124072189931741.
} 


\section{Considerações iniciais}

Para o Brasil, simbolicamente chamado "país do carnaval", sair fantasiado neste período festivo com adereços de super-herói sempre foi uma caracterização estética apreciável. Afinal, no carnaval as máscaras são permitidas e as roupas mais variadas fazem sucesso, de heróis a vilões; personagens de filmes a desenhos tornam-se um bom jeito dos adultos colocarem para fora suas paixões sem julgamentos.

Para as crianças, sempre foi aceitável uma camiseta do seu herói favorito. Nos aniversários constantemente apareciam temas, desde Ursinhos Carinhosos, desenho animado de muita audiência em 1980, até filmes como Frozen, animação de sucesso da Disney em 2012. Mas, o que falar de casamentos temáticos de super-heróis? Colações de grau com Batman, Homem Aranha, Homem de Ferro, Capitão América entre outros? Imagine, então, você andando pela rua e avistando um homem por volta de seus 40 anos usando uma camiseta com o Batman estampado, logo mais na frente uma moça, com seus 15 anos, vestida com uma camiseta da Mulher Maravilha. Duas gerações diferentes que carregam orgulhosamente seus heróis em estampa.

Seja uma blusa, uma calça, uma saia, uma bermuda e até bolsas, mochilas e sapatos, a cultura pop do mundo nerd, antes composto por um grupo de pessoas socialmente excluídas, desfila nas passarelas do dia a dia, para todos os gostos e idades em todos os públicos. Esses bens de consumo podem representar culturalmente uma sociedade visto que:

\footnotetext{
Os bens de consumo são considerados artefatos culturais criados pelos indivíduos com finalidade de expressar tanto suas singularidades individuais ou coletivas, quanto suas classificações de pertencimento social. Este é o sentido da mediação social que os bens carregam ao construírem uma combinação com o sistema simbólico que é a cultura (OLIVEIRA, 2010, p. 23).
}

Através dessa premissa, vamos analisar esse comportamento de consumo cultural que aqui chamaremos de nerd fashion, termo proposto pelos autores desse artigo a partir da concepção de mercado chamada de fast fashion (POSNER, 2015), para nominar essa moda pautada em estampas baseadas em HQs, heróis, vilões, games, filmes e animações, contextualizada pela ideia de tribalismo de Michel Maffesoli (1998; 2012), como será discutido a frente.

O tribalismo, em sua essência, é uma vontade de "estar-junto" para a qual o que importa é o compartilhamento de emoções. Isso vai formar o que Maffesoli identifica como "cultura do sentimento", baseada em relações tácteis, por formas coletivas de empatia. Essa cultura do sentimento não se inscreve mais em nenhuma finalidade, tendo como única preocupação o presente vivido coletivamente.

$\mathrm{E}$, dentro deste pensamento, percebemos que a indústria da moda se renova em moldes mais urbanos e cotidianos, voltados para um consumo de massa, exponenciado pelas 
grandes produções cinematográficas de marcas gigantes do mercado do entretenimento como Marvel, DC e Disney. Algo como o "supermercado de estilos", cunhado pelo antropólogo Ted Polhemus (MESQUITA, 2004).

Nesse horizonte de Polhemus, que remonta a um entusiasmo pela decoração do corpo, o consumo nasce das subculturas jovens e suas experiências estéticas rebeldes e da moda de rua - streetwear -, expandindo-se rapidamente como conceito industrial, ganhando as passarelas e os guarda-roupas de uma maneira geral. Polhemus faz uma antropologia do estilo na qual o consumidor faz suas misturas da maneira que bem entender, criando um mix self service de estilos.

As pessoas passam a misturar tudo, burlando os moldes e confundindo os olhares padronizados. Subvertendo e combinando novos significados em que o que existe é uma profusão de imagens e mensagens ao invés de um estilo legível - segundo Polhemus, a rua e o sujeito como referenciais de moda, destronam as diretrizes da alta-costura -, e nessa moda as pessoas têm a possibilidade de experimentar personagens, atitudes e toda forma de sentimento criativo (MESQUITA, 2004).

Não é por acaso que vamos encontrar estas experiências - ligadas à juventude e ao streetwear - utilizando o conceito de "supermercado" como linha de trabalho e como imagem de marca, nas estamparias com desenhos personalizados, potencializando pequenos quiosques de venda, como a marca Piticas, em produtos que desenham essa nova dinâmica da "cultura do sentimento", conversando com o consumidor numa linguagem com a qual ela já tem intimidade no seu dia a dia.

A loja Piticas foi inaugurada em 2008 e, na época, nem possuía licença para a produção das camisetas com estampa das grandes marcas internacionais, que possuíam os direitos autorais de personagens como Batman, Vingadores, X-Men etc. Segundo o site Economia - $i G^{3}$ a produção da fábrica da Piticas, em maio de 2016, girava em torno de 11 mil camisetas por mês, o que lhes rendeu um faturamento de R $\$ 60$ milhões em 2015 com 175 unidades espalhadas pelo Brasil. Já em 2017, a franquia possuía unidades em centros comerciais, aeroportos, galerias, rodoviárias e shoppings com um total 272 lojas, sendo sete lojas satélites e o restante de quiosques.

A Piticas percebeu bem cedo que o cenário de consumo envolvia mais do que simplesmente um público exclusivamente nerd, mas um sentimento de copertencimento que conecta pessoas umas às outras a partir de um universo que propõe representações simbólicas, cristalizando representações de coisas simples do cotidiano da vida, encontradas no que Maffesoli chama de "trocas de sentimentos, discussões de botequim, crenças populares, vilões de mundo e outras tagarelices" (MAFFESOLI, 1998, p. 19) referenciadas nas estampas das camisas.

\footnotetext{
Disponível em: http://economia.ig.com.br/financas/seunegocio/2016-05-16/irmaos-largam-pirataria-para-faturar-r-60-milhoes-com-camisetas-de-personagens.html. Acesso em: 10 abr. 2018.
} 
O que Maffesoli nos convida a questionar, e alicerça a pergunta que tentaremos responder no decorrer desse artigo, é que nesse cenário da pós-modernidade ${ }^{4}$, uma vez o individualismo substituído pela necessidade de identificação com um grupo, as massas que se diluem em tribos, ou nas tribos que se agregam em massas, provocam um reencantamento das relações e têm como cimento principal uma emoção ou uma sensibilidade vivida em comum.

Tal perspectiva nos obriga a superar a dicotomia clássica entre sujeito e objeto que fundamenta toda a filosofia burguesa. A ênfase incide, então, muito mais sobre o que une do que sobre o que separa. Não se trata mais da história que construo, contratualmente associado a outros indivíduos racionais, mas de um mito do qual participo. Podem existir heróis, santos, figuras emblemáticas, mas eles são, de certa maneira, tipos-ideais "formas" vazias, matrizes que permitem a qualquer um reconhecer-se e comungar com os outros. Dionísio, D. Juan, o santo cristão ou o herói grego, poderíamos desfiar infinitamente as figuras míticas, os tipos sociais que permitem uma estética comum e que servem de receptáculo à expressão do "nós" (MAFFESOLI, 1998, p. 15).

Esta nova conexão se daria a partir de uma ideia de socialidade, que em oposição à sociabilidade (fechada, acabada, objetiva), compõe interações voltadas para agrupamentos urbanos, dinâmicas das relações banais do cotidiano que exaltarão a multiplicidade de experiências coletivas baseadas não na homogeneização ou na institucionalização e racionalização da vida, mas no ambiente imaginário, passional, erótico e violento do cotidiano, marcado por um imaginário dionisíaco (sensual, tribal). Trata-se exatamente da interseção por onde trafegam os personagens do mundo da ficção dos super-heróis e os novos sujeitos ansiosos de compartilhar narrativas dionisíacas, através das imagens estampadas desse universo fantástico em suas camisas.

Na perspectiva desse autor, pode-se dizer que assistimos tendencialmente à substituição de um social-racionalizado por uma socialidade com dominante empática, ou polos de atração do imaginário coletivo, conectando a tribo, de forma real ou simbólica, e adquirindo com isso valor. 0 "S" de Superman no peito da camisa ganha valor de esperança; o "morcego" do Batman, de nobreza de espírito; o "M" estilizado da Mulher Maravilha, de força, e a estrela dourada da Capitã Marvel, valor de superação.

\footnotetext{
${ }^{4} 0$ conceito pós-modernidade é alvo de muita discussão nas Ciências Sociais, posto que há algumas vertentes que tentam explicá-lo. Uma dessas vertentes defendida por Lyotard (2009) sugere a pós-modernidade como um rompimento, uma ruptura com as verdades absolutas ou metanarrativas da modernidade. Uma outra vertente, defendida por Giddens (1991), considera que estamos alcançando um período em que as consequências da modernidade estão se tornando mais radicalizadas e universalizadas do que antes; esse autor prefere trabalhar com o conceito de alta-modernidade. Existe também uma terceira vertente, na qual podemos incluir o sociólogo Michel Maffesoli, que trata a pós-modernidade como um novo paradigma tentando não sugerir rupturas nem radicalização, mas sim uma reorganização de valores, ideias, visões de mundo etc. que são provenientes da modernidade.
} 
Sem dúvida, com um mercado nerd fashion em ebulição, esse "tribalismo emocional" baseado naquilo que Maffesoli chama de emoção coletiva, conduz um comportamento que além de ditar tendências de moda e prover um forte mercado varejista, traça elos para histórias comuns que, simbolizadas nas estampas de super-heróis, promovem experiências humanas compartilhadas.

\section{Quem eram os nerds antes e quem são eles hoje?}

Há algumas décadas ser chamado de "nerd" era algo pejorativo, uma ofensa, visto que o estereótipo de uma pessoa nerd era aquele excluído socialmente e com grande apreço pela cultura pop. A exclusão se dava em geral pelo grande tempo dedicado a estudos, a filmes e a livros, longe do convívio social. Esse "cara" retratado em filmes e séries como estranho ditava como devia ser o nerd e principalmente como ele devia ser tratado socialmente.

A associação do nerd como um indivíduo dotado de grande inteligência surgiu há algumas décadas e foi muito popularizada por veículos midiáticos, sobretudo durante os anos 1980. A conotação de inteligência como atributo do nerd veio concomitantemente associada à questão do deslocamento social, como se tivesse que apresentar necessariamente uma grande dificuldade de interagir socialmente (YOKOTE, 2014, p. 15).

Vários filmes e seriados retratam essa imagem do nerd como aquela pessoa "esquisita", roupas fora de moda, cores vibrantes, óculos, sempre com livros na mão e frases carregadas de referências que poucos entendiam. Essas pessoas, ditas fora do comum, eram ridicularizadas e colocadas à margem da sociedade. Porém, o termo vem se desconstruindo e se reformulando ao longo dos anos.

A palavra nerd ainda possui uma carência de definição cultural. Segundo o site da revista Exame ${ }^{5}$, ela foi incluída no Dicionário Aurélio ${ }^{6}$ apenas em outubro de 2010, o que nos encaminha à reflexão dessa ressignificação do termo nas últimas décadas visto que

Outra característica relacionada ao público nerd - que também começou a se desenvolver por volta dos anos 1970 - aquela que é cada vez mais mobilizada como atributo do sujeito nerd: a sua relação com um determinado conjunto de bens culturais. Dentre os elementos que figuram nesse conjunto, profundamente

\footnotetext{
${ }_{5}^{5}$ Mais sobre em: https://exame.abril.com.br/tecnologia/dicionario-aurelio-inclui-verbetes-geeks-595605/. Acesso em: $20 \mathrm{mar} .2018$.

6 Dicionário popular editado no Brasil e lançado originalmente em fins de 1975.
} 
imerso na cultura pop, estão sobretudo as produções audiovisuais como as séries de televisão, filmes, videogames e histórias em quadrinhos, além da literatura (YOKOTE, 2014, p. 21).

Por essa razão, é comum ainda haver vários modos de enxergar a cultura nerd, como para a entrevistada Lidia Castro, de 23 anos. Apesar das 23 camisas com estampas nerds, ao ser questionada se se considera nerd sua resposta foi: "Sei lá, acho que não. Acredito que sou bem informada apenas. Tem pessoas bem mais inteligentes por aí, acho que não sou nerd não"7. Isso mostra a comum confusão entre o significado antigo, de pessoas inteligentes, e a ressignificação que abrange a cultura pop.

Esses bens culturais se desenvolvem a partir de hábitos de consumo, construindo assim identidades não mais por imposição, mas hoje por opção afetiva. Ser nerd tornou-se motivo de orgulho, a prova disto é a grande comemoração acerca do dia 25 maio, data escolhida para comemorar a première do primeiro filme da série Star Wars, o Episódio IV: Uma nova esperança, em 1977, mas que atualmente celebra todo o universo nerd.

A transformação do nerd em um grupo intelectual e economicamente destacado na sociedade fez com que sua representação em diversos produtos culturais apresentasse mudanças. 0 nerd saiu de coadjuvante para personagem principal, o visual geek entrou em cena, mais moderno e estiloso, refletindo o atual momento de elevada autoestima pela qual a tribo urbana passa (SILVA, 2015, p. 13).

Além da carência de definição e do processo de ressignificação, a linha entre os termos nerd e geek é tênue e comumente inexistente, visto que para a grande massa de pessoas não existe diferença. Essa separação em geral é feita por consumidores fãs, um grupo menor e seleto que está imerso nesse universo nerd, que se subdivide segundo Yokote (2014) em geek, que são fãs de tecnologia, gamers, fãs de jogos eletrônicos e de tabuleiros, fandom, que são fãs de fenômenos culturais específicos como Star Wars, e otakus, que são fãs da cultura pop japonesa.

Isso se reforça na entrevista feita com Edson Viera, jornalista e professor universitário de 47 anos, que possui mais de 40 camisas nerds. Ao ser questionado se ele se considera nerd, afirmou:

Não me considero nerd, mas sempre respirei esse oxigênio. Sempre tive amigos fissurados em coisas nerd. Mas com oito anos vi Star Wars e aquilo me mudou pra sempre. E desde aquele dia resolvi viver aquele mundo. Sofri um pouco com isso.

\footnotetext{
7 Entrevista concedida por CASTRO, Lidia. Entrevista I. [20 março 2018]. Entrevistador/a: Marcus Correa e Milene Castro. Belém, 2018.
} 
Era motivo de riso na sala. Só fui superar isso com a chegada do meu filho. Ele me mostrou novos horizontes ${ }^{8}$.

Com essa ressignificação do conceito de nerd, o comportamento de consumo também muda; já não existe problema em estampar suas paixões no peito, ao contrário, está na moda. A grande movimentação na indústria cultural cinematográfica das produções de heróis impulsiona a ascensão da cultura nerd, que

[...] está em ascensão devido, entre outros fatores, a uma elasticidade da idade considerada juventude. Assim, pode-se dizer que a cultura nerd é o espelho de uma nova configuração social em que a juventude enquanto conceito é, cada vez mais, o centro das atenções (MATOS, 2011, p. 11).

Na entrevista realizada pelos autores com o advogado Fabricio Castro, de 34 anos, que possui cerca de 20 camisas, ao ser questionado quanto à motivação do uso, respondeu:

Gosto de usar camisetas dos meus personagens favoritos, pois sinto como se eles estivessem mais próximos de mim. Outras camisetas, por exemplo, as de games, principalmente as camisetas de games antigos, elas marcam uma época que eu vivi e sinto saudade 9 .

Esta resposta assemelha-se à de Edson Vieira para a mesma pergunta. Ele afirma que "há um discurso de identidade no uso das camisas. Eu cresci lendo HQ e assistindo Batman (aquele gordo, o Adam West) na TV. Então, tem uma coisa de memória afetiva"10.

É preciso olhar por outra perspectiva; além das motivações citadas acima, temos também outro grupo de consumo. Em geral, trata-se de um núcleo mais novo, como Lidia, que tem como motivação o pai, que usava as coisas nerds. Outro entrevistado, Rafael Veiga, de 19 anos, possui 16 camisas e usa "por gostar dos personagens" ${ }^{\prime 1}$.

\footnotetext{
${ }^{8}$ Entrevista concedida por VIEIRA, Edson. Entrevista II. [20 março 2018]. Entrevistador/a: Marcus Correa e Milene Castro. Belém, 2018.

${ }^{9}$ Entrevista concedida por CASTRO, Fabrício. Entrevista III. [20 março 2018]. Entrevistador/a: Marcus Correa e Milene Castro. Belém, 2018.

${ }^{10}$ Entrevista concedida por VIEIRA, Edson. Entrevista II. [20 março 2018]. Entrevistador/a: Marcus Correa e Milene Castro. Belém, 2018.

${ }^{11}$ Entrevista concedida por VEIGA, Rafael. Entrevista IV. [20 março 2018]. Entrevistador/a: Marcus Correa e Milene Castro. Belém, 2018.
} 
Vemos aqui pelo menos dois grupos de consumo que serão analisados, o que nos propõe um cenário com pessoas de diferentes idades se reunindo em um grupo social por suas preferências, não importando a motivação ou fatores externos além do consumo voluntário. Esse consumo traduz relações sociais, classificando grupos, seja por afeição ou apenas tendência, como discutiremos mais à frente. Neste caso, criam-se e recriam-se símbolos culturais gerando uma demanda cada vez maior por esses produtos que estão "na moda", desenvolvendo assim identidades:

\begin{abstract}
Em toda parte estão emergindo identidades culturais que não são fixas, mas que estão suspensas, em transição, entre diferentes posições; que retiram seus recursos, ao mesmo tempo, de diferentes tradições culturais; e que são o produto desses complicados cruzamentos e misturas culturais que são cada vez mais comuns num mundo globalizado (HALL, 2011, p. 88).
\end{abstract}

Essas identidades culturalmente criadas, apesar de individuais tornam-se coletivas, unindo e movimentando grupos por aproximação dos interesses. 0 nerd de antes, estereotipado como excluído, hoje é antenado e dita moda e cultura, influenciando em discurso, aparência e consumo através das preferências pessoais e coletivas. Afinal, está na moda ser nerd, não é?

\title{
Moda e consumo
}

Exatamente como nos disse Lipovestsky (2009) em sua seminal obra $O$ império do efêmero, estamos imersos na moda, a qual ele chama de era da moda consumada, quando sua influência se expande a instâncias cada vez mais vastas da vida coletiva e cotidiana. É o espetáculo da democracia e da indústria, dirá Debord (1997), alertando-nos para a "sobrevivência aumentada" como âncora de um tempo pós-moderno: a sedução e o efêmero tornam-se os princípios organizadores da vida urbana.

Quando se pensa sobre o consumo, pensa-se em pós-modernidade e na formação de um indivíduo e sua identidade. Para Svendsen (2010), não se consome para suprir as tão somente conhecidas necessidades preexistentes do ser humano. Consome-se para criar identidade. 0 autor ainda complementa que, além disso, o consumo funciona como um tipo de entretenimento. É um meio cada vez mais usual de combater o tédio.

E como entretenimento, Lipovestsky (2009) torna a moda um dos meios mais proeminentes para exaltação do consumo e espetacularização do indivíduo, em que este vive cercado por produtos e imagens e estabelece com eles uma relação cada vez mais simbólica.

Pode-se caracterizar empiricamente a "sociedade do consumo" por diferentes traços: elevação do nível da vida, abundância das mercadorias e dos serviços, culto dos objetos e dos lazeres, moral hedonista e materialista etc. Mas, estruturalmente, é a generalização do processo da moda que a define propriamente (LIPOVETSKY, 2009, p. 184). 
Ademais, no consumo, mais especificamente no consumo de moda, encontramos um relacionamento baseado no prazer e no bem-estar. Svendsen (2010, p. 129) descreve o "hedonista moderno, como romântico que vive no imaginário e para o imaginário, transformando-se por fim no consumidor pós-moderno".

Reforça-se então o conceito de uma sociedade de consumo que se vê abarrotada de significado, constituída de elementos que auxiliarão na formação da identidade do indivíduo. A moda, então, passa a ser uma estratégia de demonstração, de similarização, de expressão e, com essas informações, o indivíduo identifica e é identificado pelos outros do grupo (AVELAR, 2011).

Nesse aspecto, Godart (2010) afirma que a moda se encontra em uma constante dinâmica dos opostos da vida social e psicológica, com a universalidade e a particularidade, ou ainda a criação e a destruição. Portanto, a moda é o que une o coletivo com a individualidade, fazendo com que o indivíduo se sinta dentro de determinado grupo.

Featherstone (1995) nos alerta pertinentemente que questões de desejo e prazer, satisfações emocionais e estéticas derivadas das experiências de consumo não devem ser encaradas simplesmente como uma lógica de manipulação psicológica, que celebre o populismo de massa e a desordem cultural. Para este sociólogo, "há a questão dos prazeres emocionais de consumo, os sonhos e os desejos celebrados no imaginário cultural consumista e em locais específicos de consumo que produzem diversos tipos de excitação física e prazeres estéticos" (FEATHERSTONE, 1995, p. 31). Essa lógica do consumo que incrementa um filão cultural e estético, aponta para uma ênfase na estetização da vida cotidiana, que segundo Featherstone apaga as fronteiras entre arte e vida cotidiana, provocando uma "promiscuidade lúdica de códigos" (FEATHERSTONE, 1995, p. 97).

Não custa lembrar, como esclarece Fritjof Capra (1996) em A teia da vida, que nós pensamos com emoções, baseados na experiência de vida e conectados com um ambiente de miscelâneas estilísticas ecléticas, onde o adulto descobre o velho no novo e a criança o novo de novo.

\section{A moda nerd fashion}

Entendendo que a sociedade de consumo se torna essencialmente cultural, Mike Featherstone (1995) nos diz que, na medida em que a vida social fica desregulada, as relações sociais tornam-se mais variáveis e menos estruturadas por normas estáveis. Este autor ainda considera que a estetização da vida cotidiana das grandes cidades proporciona à arte a oportunidade de se deslocar para a indústria, na qual a publicidade, o marketing e o design produzem uma nova paisagem urbana estetizada.

Assim, o avanço dos meios de comunicação de massa, principalmente no universo cinematográfico, proporcionou uma divulgação das tendências da moda e um desejo de segui-las na população, caracterizando uma influência no vestuário e no estilo das pessoas. Surge, então, a moda pré-fabricada que acaba virando uma necessidade de todos, sendo vendida, através desses meios, para milhões de pessoas. Esse tipo de mercado chama-se fast fashion, no qual grandes lojas adaptam as grandes tendências ao mercado de massa (POSNER, 2015).

Neste contexto, busca-se os nerd fashions, público consumidor que se divide em dois grupos: o primeiro grupo, que consome por paixão os produtos de moda, lê histórias em 
quadrinhos, coleciona HotToys ${ }^{12}$ e assiste filmes de heróis; e o segundo grupo, que consome os produtos por tendência e por estarem na moda, sem se preocupar com a história dos personagens por trás de cada artigo produzido.

Ao primeiro grupo, reserva-se o entendimento da identidade dos personagens e de distingui-los, tanto dentro como fora das grandes telas. Assim, o indivíduo absorve as características do personagem carregando no peito a sua identificação e sua relação com a entidade homenageada. Esse público entende as referências e não usa os produtos apenas como um artigo de moda, mas como um produto cheio de significado. Além do mais, esse grupo também consome esse tipo de artigo para colecionar ou como uma forma de recordar algum momento especial já vivido.

O segundo grupo é entendido como um público que utiliza os produtos, não por buscar referências dos personagens, mas por serem tendência de moda e para tentar fazer parte de um determinado grupo ou tribo. Nesse mesmo grupo, existem indivíduos que frequentam os ambientes de cultura nerd por curiosidade ou por lazer.

Assim, surgem as lojas especializadas em satisfazer o desejo desse grupo de consumidores, como a loja Piticas (figura 1), que a cada estreia cinematográfica lança uma coleção de produtos voltada para o novo filme.

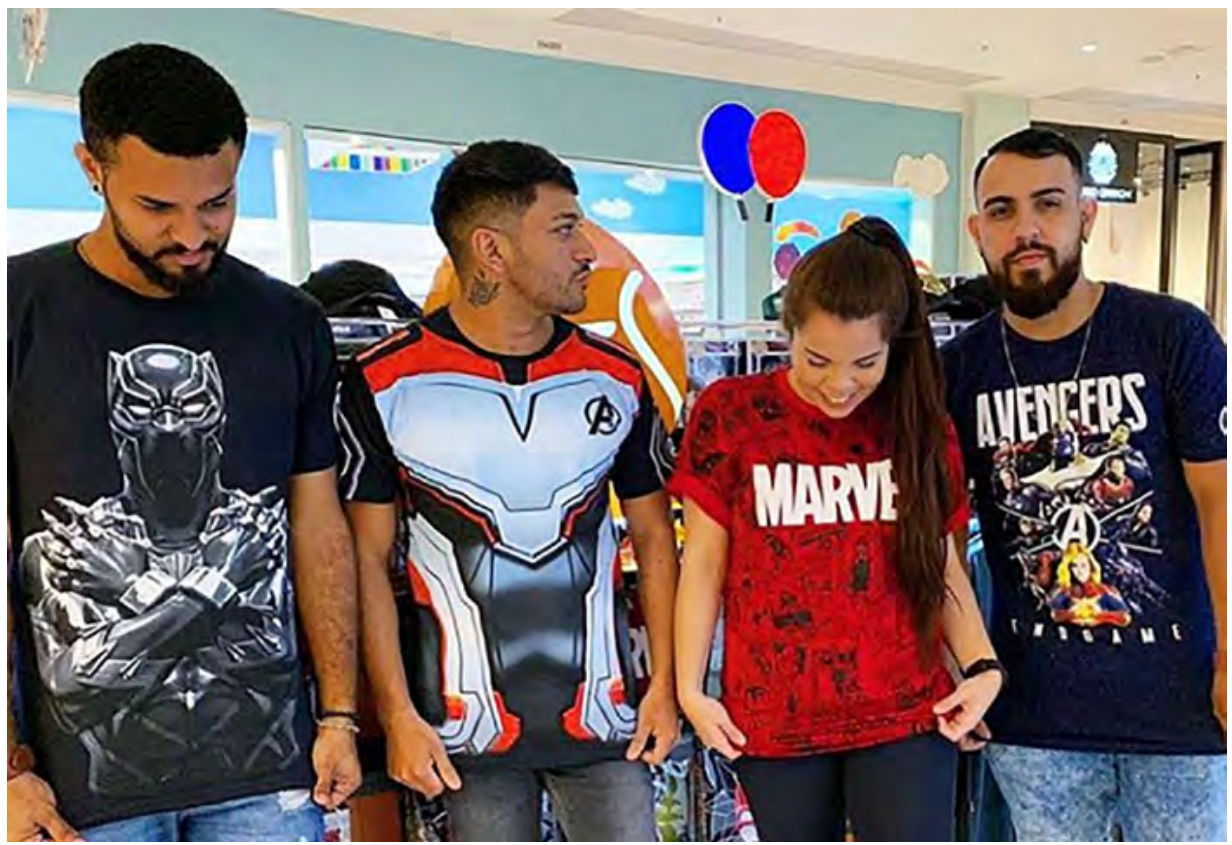

FONTE: PITICAS BELÉM. Coleção nova dos \#vingadoresultimato em todas @piticasbelem, corre \#pitifã que tá saindo num estalar de dedos. Belém, 4 abr. 2019. Instagram: @piticasbelem. Disponível em: https://www.instagram.com/p/Bv200ubhDet/?hl=pt-br. Acesso em: 4 jul. 2019.

\footnotetext{
${ }^{12}$ Bonecos e colecionáveis de luxo.
} 
Outro caso no mercado são as lojas de departamento, como a rede de lojas Riachuelo, que dispõe de uma seção fixa voltada para este público e com lançamentos constantes de novos produtos, desde camisetas a squeezes e também estojos com temas de personagens e heróis do momento. A mesma rede de lojas ainda participa anualmente de eventos ligados ao universo cinematográfico, como a Comic Com XP, em São Paulo.

Nesse contexto, portanto, percebe-se que os nerd fashions são novos consumidores, em novo segmento mercadológico, com produtos estampados com personagens de histórias em quadrinhos ou do cinema. Estes consumidores, mesmo em dois grupos distintos de identidade, se unem em um mesmo propósito, o de se firmarem dentro de uma tribo ou grupo social.

Expoentes de peso também abocanham esse cenário. A prova disso é a coleção preparada pela marca Adidas (figura 2), mundialmente conhecida pela produção de artigos e moda esportiva, que teve o lançamento de camisas inspiradas em super-heróis da Marvel, usando o aquecimento do mercado por causa da Copa do Mundo de 2018 e a estreia do novo filme da franquia Vingadores, Guerra Infinita, marcado para o final de abril de 2019, para atingir um público até então não visto como consumidor dos seus produtos. Apesar das camisas estarem sendo produzidas apenas em tamanho infantil, ninguém se surpreenderia se elas também saíssem em uma edição para adultos.
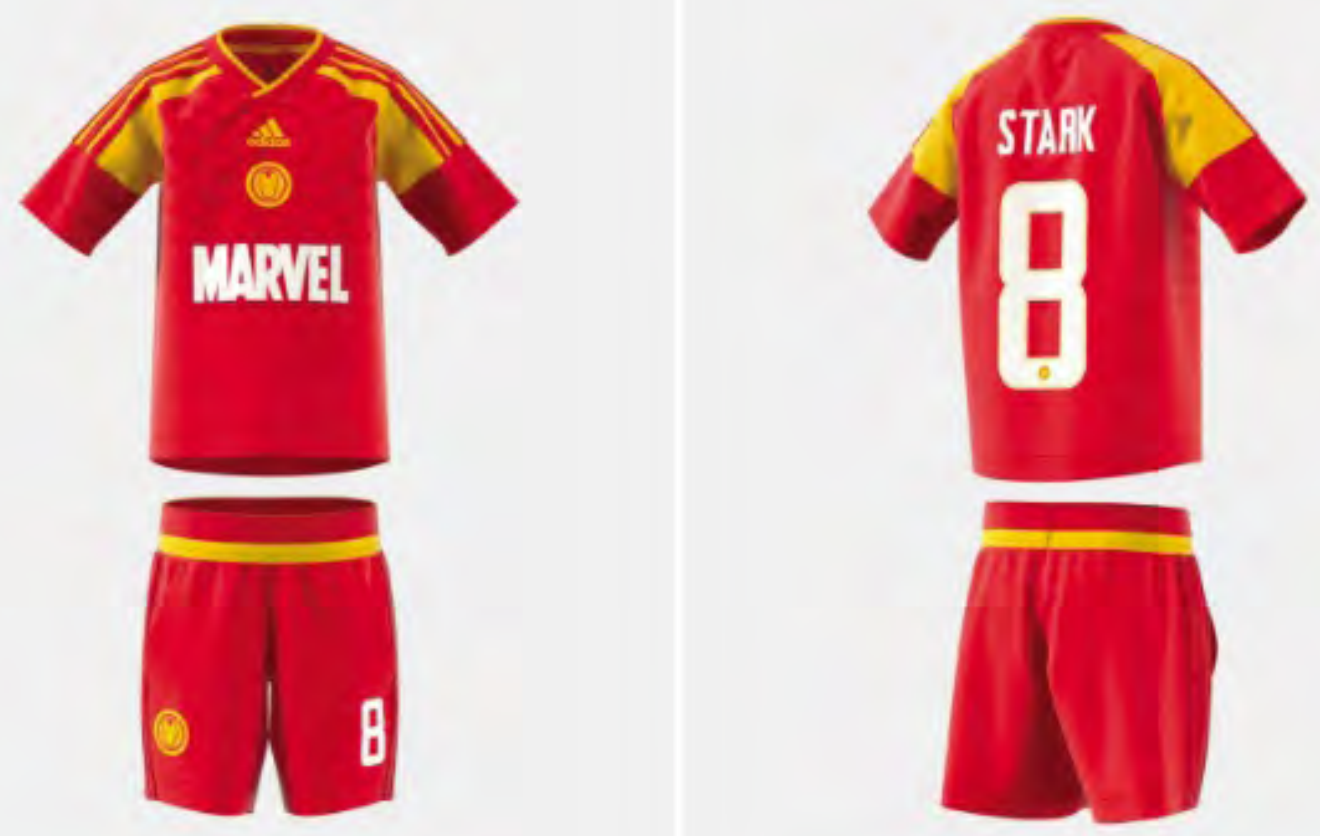

FONTE: ADIDAS. Conjunto Futebol Marvel Iron Man. 2018. Disponível em: https://www.adidas.com.br/ conjunto-futebol-marvel-iron-man/DI0199.html. Acesso em: 17 abr. 2018. 
Segundo pesquisa ${ }^{13}$ realizada em janeiro de 2018 pelo Omelete Group e o Ibope CONECTA para mapear o público de cultura pop e entretenimento no Brasil, a maior parte dos fãs tem de 22 a 39 anos (66\%), mora no Sudeste (60\%), tem ensino superior completo, pós-graduação, mestrado ou doutorado (52\%) e tem renda familiar entre 2 e 15 salários mínimos (26\%). A maioria é homem (83\%), com um pequeno avanço das mulheres em relação a 2016, quando eram $15 \%$ e agora são $17 \%$.

0 consumo do nerd fashion tem crescido com o grande investimento em produções cinematográficas dos últimos anos, e a mudança cultural acaba sendo o grande impulso para esse mercado:

\begin{abstract}
Para entender o consumo é preciso conhecer como a cultura constrói essa experiência na vida cotidiana, como atuam os códigos culturais que dão coerência às práticas e como, através do consumo, classificamos objetos e pessoas, elaboramos semelhanças e diferenças. 0 consumo é um sistema simbólico que articula coisas e seres humanos, como tal, uma forma privilegiada de ler o mundo que nos cerca. Através dele a cultura expressa princípios, estilos de vida, ideias, categorias, identidades sociais e projetos coletivos. Ele é um dos grandes inventores das classificações sociais que regulam as visões de mundo e talvez, nenhum outro fenômeno espelhe com tanta adequação um certo espírito do tempo - face definitiva de nossa época (ROCHA, 2000, p. 19).
\end{abstract}

Esse consumo, como vimos, parte do que Maffesoli chama de tribalismo emocional, pois se trata de uma categoria que pode servir como reveladora desta situação, identificando pontos como aspectos efêmeros, composição cambiante, inscrição local e estrutura cotidiana. Nessa perspectiva, na pós-modernidade as massas que se diluem em tribos, ou as tribos que se agregam em massas, constituem um reencantamento que tem como cimento principal uma emoção ou uma sensibilidade vivida em comum.

Então, os super-heróis, apesar de seus superpoderes, têm na sua essência o traço da cotidianidade. 0 Homem Aranha antes de prender o Dr. Octopus precisa fazer o dever de casa, levar leite para Tia May e ainda ir ao cinema com Mary Jane. No Quarteto Fantástico, o Sr. e a Sra. Richards precisam fazer o jantar e arrumar as crianças na cama, antes de sair para salvar a terra. Diz Maffesoli (2012), o coração que bate da cotidianidade é o copertencimento.

Este sentido de mediação, imbrincado na perspectiva da vida cotidiana, nos conecta ao conceito de "tribalização" defendido por Michel Mafesoli, que propõe uma valorização do fluido, do simples, do polimorfo, aderindo uma perspectiva relativa ao papel da afetividade, da proximidade, do calor humano na constituição do social.

\footnotetext{
${ }^{13}$ Disponível em: http://escolabrasileiradegames.com.br/blog/pesquisa-mapeia-habitos-e-comportamentos-do-consumidor-de-cultura-pop-no-brasil. Acesso em: 22 mar. 2018.
} 
Como tribo, Maffesoli (2012) entende grupos sociais que se deslocam dentro do processo de massificação da sociedade moderna, não sendo estáticos, pelo contrário, visando constante transformação. E, se a sociedade é maleável, afirma, é porque é composta por seres humanos, que têm motivações diversas. São instáveis e podem se deslocar para contextos diferentes.

\section{Considerações finais}

Estamos em um tempo nerd, cenário montado pelo universo cinematográfico das grandes marcas, mas, principalmente, estamos num tempo de afetividades compartilhadas, portanto, os indivíduos na contemporaneidade se entrelaçam naquilo que Maffesoli (2012) chama de emoção coletiva. 0 sociólogo francês ainda pondera que, uma vez que essa comunidade emocional está condicionada ao sentimento dos atores sociais, ela está propensa a mudanças efêmeras.

O ser humano busca a proximidade com aqueles que pensam e sentem como ele; Walter Benjamin (1987) afirma que existe uma espécie de aura sobre esse sentimento que cria as comunidades emocionais. Como regulador desse emaranhado de sentimentos está a ética que, para Maffesoli (1998, p. 29), é “cimento que fará com que diversos elementos de um conjunto dado formem um todo".

O consumo da moda nerd fashion é divido em dois grupos. 0 primeiro é das pessoas que compram pela paixão ao universo nerd, que conhecem os personagens, histórias e geralmente consomem muito além de roupas e de acessórios. Mergulham em diversos produtos ligados a HQs, filmes, séries e livros. 0 segundo grupo compra por tendência, motivado pela grande avalanche da indústria cinematográfica. Em resumo, compra por estar na "moda".

Apesar das motivações de compra, existe algo além da divisão dos grupos expostos que possibilita que pessoas de gerações, de classes e de perfis de consumo diferentes acabem fazendo parte da mesma experiência emocional em que o comportamento afetivo motiva a compra da moda nerd fashion, uma compra para pertencer.

Essa comunidade emocional está ligada pelo querer fazer parte, pois cada vez mais pode se sentir próxima, através da moda que se veste. Isso torna o consumo da moda além do simples vestir, mas uma forma de se afirmar, de copertencer e significar o mundo ao redor.

Esse segmento mercadológico está longe de se esgotar. Ele vai se ressignificar, assim como o conceito de nerd se ressignificou, ao passar de "pessoa estranha" para amantes da cultura pop. 0 consumo é então, além do ato de comprar, ato de afirmar sua identidade, de pertencer a um grupo, de estar dentro do que acontece fora, uma individualização para então fazer parte. 


\section{Referências}

AVELAR, Suzana. Moda e globalização. São Paulo: Estação Letras e Cores, 2011.

BENJAMIN, Walter. Magia e técnica, arte e política: ensaios sobre literatura e história da cultura. Obras escolhidas. v. 1. Tradução Sérgio Paulo Rouanet. 3. ed. São Paulo: Editora Brasiliense, 1987.

CAPRA, Fritjof. A teia da vida: uma nova compreensão cientifica dos sistemas vivos. Tradução Newton Roberval Eichemberg. 11. ed. São Paulo: Editora Cultrix, 1996.

DEBORD, Guy. Sociedade do espetáculo. Tradução Estela dos Santos Abreu. Rio de Janeiro: Contraponto, 1997.

FEATHERSTONE, Mike. Cultura do consumo e pós-modernismo. Tradução Júlio Assis Simões. São Paulo: Studio Nobel, 1995.

GIDDENS, Anthony. As conseqüências da modernidade. Tradução Raul Fiker. São Paulo: UNESP, 1991.

GODART, Frédéric. Sociologia da moda. Tradução Leia P. Zylberlicht. São Paulo: Editora Senac São Paulo, 2010.

HALL, Stuart. A identidade cultural na pós-modernidade. Tradução Tomaz Tadeu da Silva e Guaraci Lopes Louro. 11. ed. Rio de Janeiro: DP\&A, 2011.

LIPOVETSKY, Gilles. 0 império do efêmero. Tradução Maria Lúcia Machado. 7. ed. São Paulo: Companhia das Letras, 2009.

LYOTARD, Jean-François. A condição pós-moderna. Tradução Ricardo Correa Barbosa. 12. ed. Rio de Janeiro: José Olympio, 2009.

MAFFESOLI, Michel. 0 tempo das tribos: o declínio do individualismo nas sociedades de massas. Tradução Maria de Lourdes Menezes. 2. ed. Rio de Janeiro: Forense Universitária, 1998.

MAFFESOLI, Michel. 0 tempo retorna: formas elementares da pós-modernidade. Tradução Teresa Dias Carneiro. Rio de Janeiro: Forense Universitária, 2012.

MATOS, Patrícia. 0 nerd virou cool: identidade, consumo midiático e capital simbólico em uma cultura juvenil em ascensão. In: CONGRESSO DE CIÊNCIAS DA COMUNICAÇÃO NA REGIÃO SUDESTE, 16., 2011, São Paulo. Anais [...]. São Paulo: Intercom, 2011, p. 1-15. Disponível em: http://www.intercom.org.br/papers/regionais/sudeste2011/resumos/ r24-1149-1.pdf. Acesso em: 3 mar. 2018. 
MESQUITA, Cristiane. Moda contemporânea: quatro ou cinco conexões possíveis. São Paulo: Editora Anhembi Morumbi, 2004.

OLIVEIRA, Josiane Silva de. o "olhar" antropológico do marketing: contribuições da antropologia do consumo ao entendimento do sistema de produção de bens e do comportamento do consumidor. Revista ADM.MADE, v. 14, n. 2, p. 21-35, maio/agosto 2010. Disponível em: http://revistaadmmade.estacio.br/index.php/admmade/article/ view/50. Acesso em: 14 fev. 2018.

POSNER, Harriet. Marketing de moda. Tradução Márcia Longarçol. São Paulo: Editora G. Gili, 2015.

ROCHA, Everardo. Totem e consumo: um estudo antropológico de anúncios publicitários. Revista Alceu, v. 1, n. 1, p. 18-37, jul./dez. 2000. Disponível em: http://criancaeconsumo.org. br/wp-content/uploads/2017/03/Totem-e-Consumo.pdf. Acesso em: 22 mar. 2018.

SVENDSEN, Lars. Moda: uma filosofia. Tradução Maria Luiza X. de A. Borges. Rio de Janeiro: Zahar, 2010.

SILVA, Soraya Madeira. Evolução da identidade, estereótipo e imagem midiática da tribo urbana dos nerds. In: INTERPROGAMAS DE MESTRADO DA FACULDADE CÁSPER LÍBERO, 10., 2015, São Paulo. Anais [...] São Paulo: Faculdade Cásper Líbero, 2015. Disponível em: https://casperlibero.edu.br/wp-content/uploads/2015/01/Soraya-Madeira.UFC_.pdf. Acesso em: 27 abr. 2018.

YOKOTE, Guilherme Kazuo Lopes. 0 mundo dos nerds: imagens, consumo e interação. 2014. Dissertação (Mestrado em Antropologia Social) - Faculdade de Filosofia, Letras e Ciências Humanas, Universidade de São Paulo, São Paulo, 2014. Disponível em: http://www. teses.usp.br/teses/disponiveis/8/8134/tde-19052015-133604/. Acesso em: 27 mar. 2018. 